Annals of International Medical and Dental Research

E-ISSN: 2395-2822 | P-ISSN: 2395-2814

Vol-8, Issue-1 | January-February 2022

DOI: 10.53339/aimdr.2022.8.1.1

Page no- 01-06 | Section- Research Article (Physiology)

\title{
Assessment of Effect of Exercise on Body Composition in Obese and Overweight
}

\author{
L. Reshma Shireesha ${ }^{1}$, Obulesu ${ }^{2 *}$
}

${ }^{1}$ Assistant Professor, Department of Physiology, Siddhartha Medical College Vijayawada, Vijayawada, Andhra Pradesh, India.

Email: sirishareshma@gmail.com, Orcid ID: 0000-0002-7123-8070

2Medical Superintendent, Fathima Medical College Kadapa, India. Email: drlcobulesu@gmail.com, Orcid ID: 0000-0002-6505-8583
Abstract
Background: Aim: To assess the effect of exercise on body composition in obese and overweight. Methods: A total of seventy- two overweight subjects of either gender were enrolled for the study. Two groups were prepared. One group was experimental group $(n=36)$ and the second group was control group $(n=36)$. Parameter such as age, height and weight was recorded. On the basis of variables body mass Index and body fat percentage of every subject was determined. The experiment group were put on aerobic exercises spread over duration of four weeks. Results: The mean height in group I was $163.7 \mathrm{~cm}$ and $165.4 \mathrm{~cm}$ in group II. Weight was $65.2 \mathrm{~kg}$ and 63.5 $\mathrm{kgs}$ in group II, BMI $(\mathrm{Kg} / \mathrm{m} 2)$ was 29.4 and 29.1 , body fat was $29.3 \%$ and $29.6 \%$ in group I and II respectively. A significant difference was observed $(\mathrm{P}<0.05)$. The mean pre- test BMI was 29.6 and 38.5 and post- test value was 26.4 and 38.9 in group I and II respectively. A significant difference was observed $(\mathrm{P}<0.05)$. Conclusions: Regular physical activity appears to confer a health benefit to the people. There was a positive relationship between aerobic exercises and overweight women in order to reduce the value of fat in the body.

Received: 25 June 2021

Revised: 25 July 2021

Accepted: 05 August 2021

Published: 22 December 2021

Keywords:- Exercise, Obese, Overweight.

\section{INTRODUCTION}

Leading a happy and a successful life is the innate quest of all human beings. Good physique and sound health are the prerequisites to satisfy this human desire. One may take part in exercise to achieve optimal physical fitness.[1] It is a matter of common observation that majority of us particularly among female folk leads sedentary life and findings of the research states that in sedentary lifestyle the human health is obviously prone to various unfavorable situations like obesity, weight gain, hypertension and other chronic diseases. [2]
Recent studies have described several interventions for obesity, including diet, physical activity or exercise, behavioral therapy, and medication. [3] Among the various behavioral strategies, exercise interventions can provide effective weight maintenance, weight loss, weight maintenance after loss, and reduction of obesity. ${ }^{4}{ }^{4]}$ However, exercise alone has a limited effect on the body weights of individuals with obesity. Furthermore, the guidelines for how much physical activity and exercise are needed to improve health are widely known to the public as well as researchers, but they are too general to specifically address obesity, and the effects are 
Annals of International Medical and Dental Research

E-ISSN: 2395-2822 | P-ISSN: 2395-2814

Vol-8, Issue-1 | January-February 2022

DOI: 10.53339/aimdr.2022.8.1.1

Page no- 01-06 | Section- Research Article (Physiology)

variable and often inconsistent. Thus, it is necessary to understand the magnitude of the effects that physical activity or exercise interventions have on obesity.[]

Research suggested that effective management of body composition needs the harmonization of numerous characteristics including proper diet, stress management and more significantly adequate amount of exercise.[6] Considering this, the present study aimed at assessing effect of exercise on body composition in obese and overweight.

\section{MATERIAL AND METHODS}

The work was done at Govt general hospital and in the Dept at sidhartha medical college Vijayawada during 2018 and 2019. A total of seventy- two overweight subjects of either gender were enrolled for the study. The study protocol was approved from institutional ethical committee. All subjects were made aware of the study and their written consent was obtained.

Data such as name, age, gender etc. was recorded. Two groups were prepared. One group was experimental group $(n=36)$ and the second group was control group $(n=36)$. Parameter such as age, height and weight was recorded. On the basis of variables body mass Index and body fat percentage of every subject was determined. The experiment group were put on aerobic exercises spread over duration of four weeks. The control group was given no treatment. Results of the present study after recording all relevant data were subjected for statistical inferences using chi- square test. The level of significance was significant if $p$ value is below 0.05 and highly significant if it is less than 0.01 .

\section{RESULTS}

The mean height in group I was $163.7 \mathrm{~cm}$ and $165.4 \mathrm{~cm}$ in group II. Weight was $65.2 \mathrm{~kg}$ and $63.5 \mathrm{kgs}$ in group II, BMI $(\mathrm{Kg} / \mathrm{m} 2)$ was 29.4 and 29.1 , body fat was $29.3 \%$ and $29.6 \%$ in group I and II respectively. A significant difference was observed $(\mathrm{P}<0.05)$. [Table 1 , Figure 1].

The mean pre- test BMI was 29.6 and 38.5 and post- test value was 26.4 and 38.9 in group I and II respectively. A significant difference was observed $(\mathrm{P}<0.05)$. [Table 2, Figure 2].

Table 1: Demographic variables

\begin{tabular}{|l|l|l|l|}
\hline Parameters & Group I & Group II & P value \\
\hline Height $(\mathrm{cm})$ & 163.7 & 165.4 & $>0.05$ \\
\hline Weight $(\mathrm{Kg})$ & 65.2 & 63.5 & $>0.05$ \\
\hline BMI $(\mathrm{Kg} / \mathrm{m} 2)$ & 29.4 & 29.1 & $>0.05$ \\
\hline Body fat \% & 29.3 & 29.6 & $>0.05$ \\
\hline
\end{tabular}

Table 2: Pre and post-test results in body mass index

\begin{tabular}{|l|l|l|l|}
\hline Duration & Group I & Group II & P value \\
\hline Pre- test & 29.6 & 38.5 & $<0.05$ \\
\hline Post- test & 26.4 & 38.9 & $<0.05$ \\
\hline
\end{tabular}


Annals of International Medical and Dental Research

E-ISSN: 2395-2822 | P-ISSN: 2395-2814

Vol-8, Issue-1 | January-February 2022

DOI: 10.53339/aimdr.2022.8.1.1

Page no- 01-06 | Section- Research Article (Physiology)

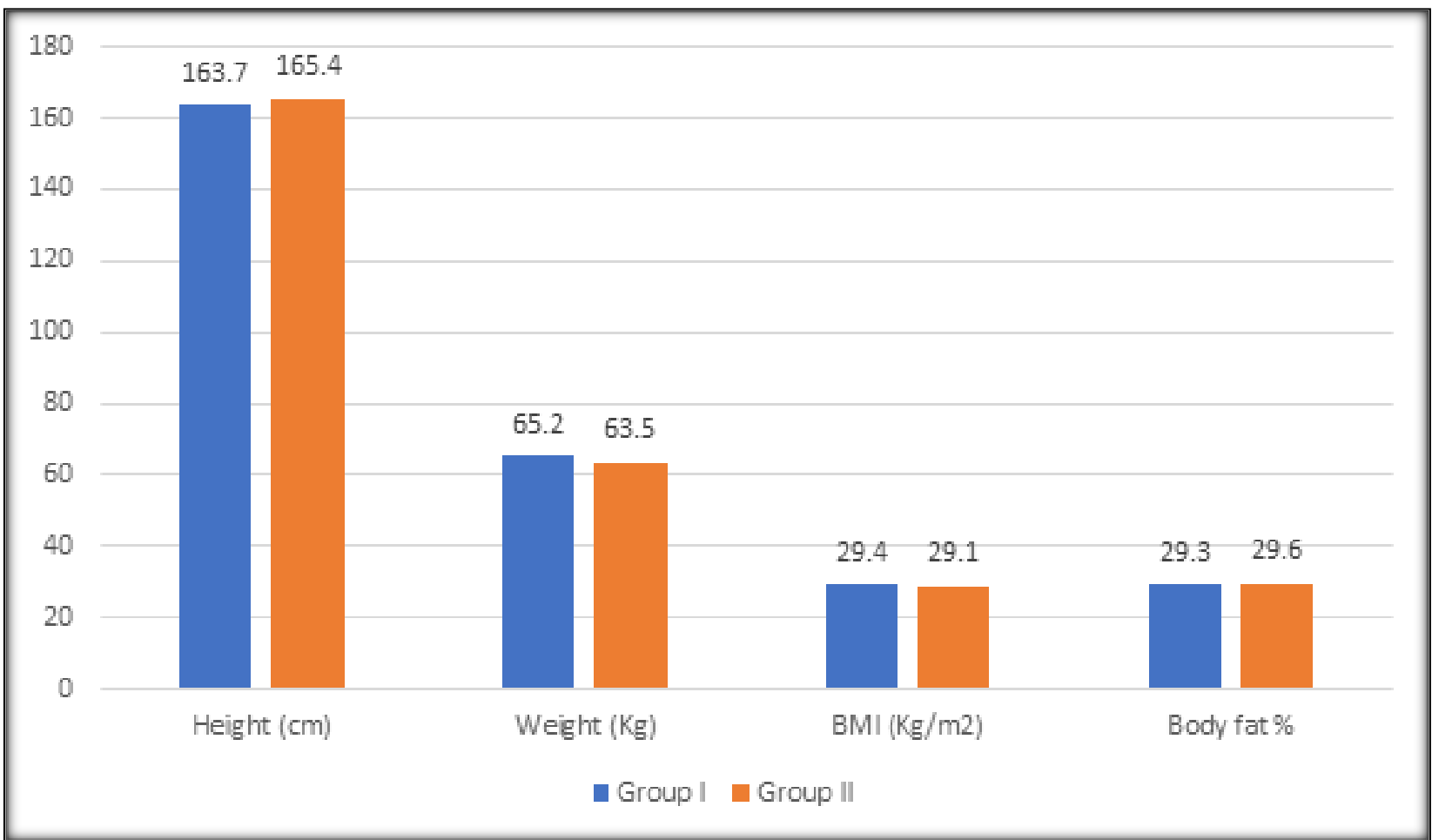

\section{Figure 1:}

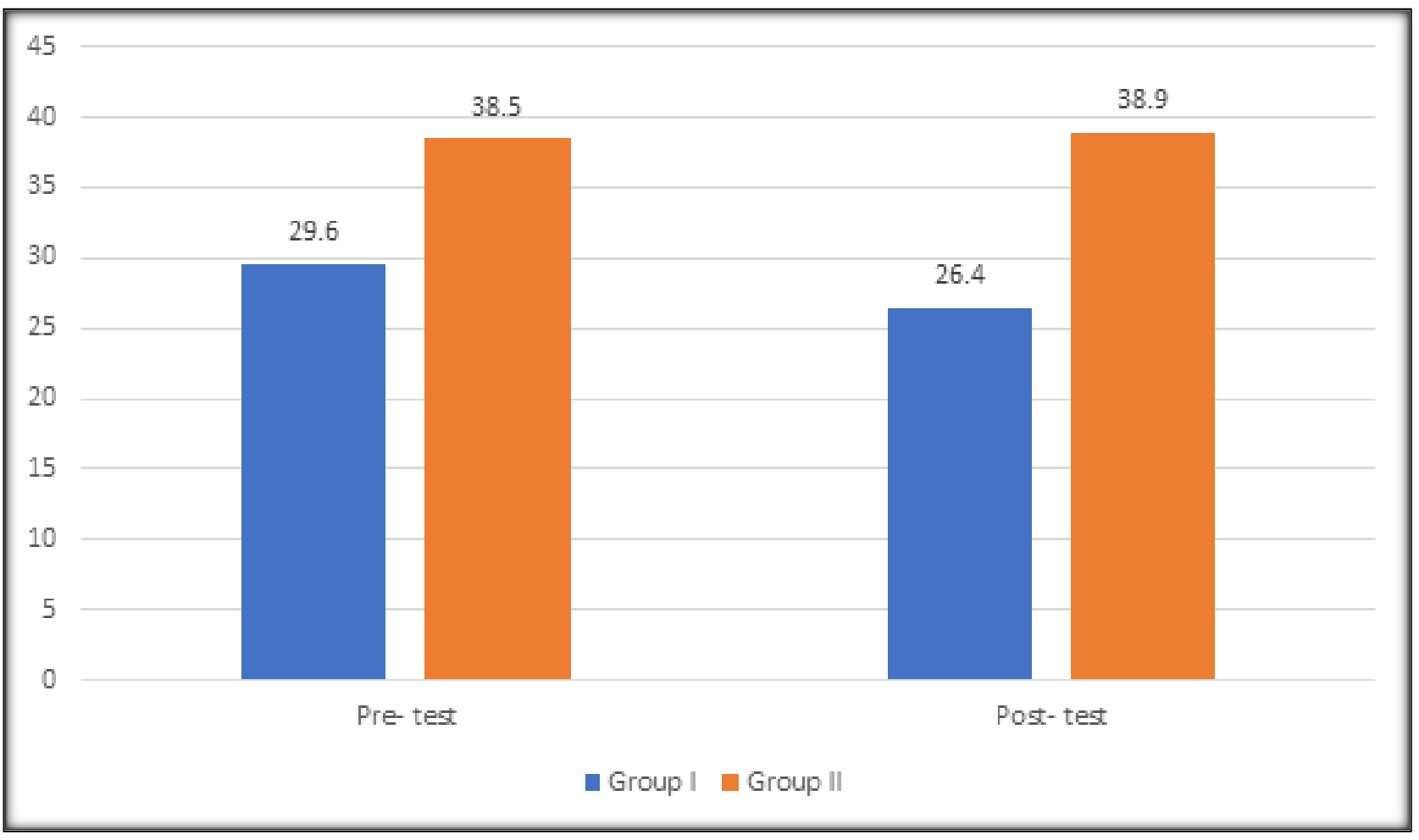

Figure 2: 
Annals of International Medical and Dental Research

E-ISSN: 2395-2822 | P-ISSN: 2395-2814

Vol-8, Issue-1 | January-February 2022

DOI: 10.53339/aimdr.2022.8.1.1

Page no- 01-06 | Section- Research Article (Physiology)

\section{DISCUSSION}

The percentage of the population that is obese increased in both the developed and developing countries. Obesity is defined as a condition of abnormal or excessive body fat (i.e., the accumulation of adipose tissue) to the extent that health may be impaired.77 Studies have demonstrated that obesity is linked to higher risk of developing various chronic diseases, such as cardiovascular disease, type 2 diabetes mellitus, and cancers. [8] Aerobic exercise increases peak oxygen consumption (VO2 peak), which is closely correlated with total body fat percentage $(\mathrm{BF} \%)$; aerobic exercise is also a powerful strategy for weight loss, particularly body fat loss. When designing a suitable weight loss program, exercise duration and intensity are generally manipulated.9] Moderate aerobic exercise for at least 150 min per week may improve risk factors for metabolic syndrome like body composition, insulin resistance and glycated haemoglobin (HbA1c). American College of Sports Medicine suggested that long-term moderate aerobic exercise for $>150$ or $200-300$ min per week can significantly reduce body weight when the diet is not controlled.[10] However, when exercise intensities differ, exercise expenditure is not the only factor responsible for weight loss. The effects of increasing exercise intensity on weight loss when exercise duration is kept constant remain unknown.[11] The present study aimed at assessing effect of exercise on body composition in obese and overweight.

Our study enrolled 72 subjects of both genders. It comprised of 40 males and 36 females. Chiu et al,[12] compared the effects of different aerobic exercise intensities and energy expenditures on the body composition of sedentary obese college students. Forty-eight obese participants [body mass index (BMI) $\geq 27$ $\mathrm{kg} / \mathrm{m} 2$, age 18-26 years] were randomized into four equal groups $(\mathrm{n}=12)$ : light-intensity training group (LITG), 40\%-50\% heart rate reserve (HRR); middle intensity training group (MITG), 50\%-70\% HRR; high-intensity training group (HITG), 70\%-80\% HRR; and control group (CG). The aerobic exercise training program was conducted for $60 \mathrm{~min}$ per day on a treadmill 3 days per week for 12 weeks. All participant anthropometric data, blood biochemical parameters, and health-related physical fitness components were measured at baseline and after 12 weeks. At baseline, the anthropometric indices did not differ significantly among the four groups ( $p>0.05)$. After 12- week exercise intervention, the HITG and MITG had significantly more changes in body weight, waist circumference (WC), waistto-hip ratio (WHR), and waist-to-height ratio (WHtR) than the LITG. The changes in BMI and body fat percentage differed among all four groups ( $\mathrm{p}<0.05)$. A 12-week highintensity exercise intervention with high energy expenditure can considerably reduce body weight, body fat, WC, WHR, and WHtR, whereas a light-intensity exercise intervention can significantly reduce body weight and body fat.

We observed that the mean height in group I was $163.7 \mathrm{~cm}$ and $165.4 \mathrm{~cm}$ in group II. Weight was $65.2 \mathrm{~kg}$ and $63.5 \mathrm{kgs}$ in group II, BMI (Kg/m2) was 29.4 and 29.1 , body fat was $29.3 \%$ and $29.6 \%$ in group I and II respectively. Pawaz et al,[13] assessed the effects of aerobic exercise on body composition of overweight female aging 22-27 years. A sample of $n=30$ 
Annals of International Medical and Dental Research

E-ISSN: 2395-2822 | P-ISSN: 2395-2814

Vol-8, Issue-1 | January-February 2022

DOI: 10.53339/aimdr.2022.8.1.1

Page no- 01-06 | Section- Research Article (Physiology)

(thirty) overweight female aging 22-27 years. A four (04) week exercise protocol was prepared and used among females of the experimental group. The experimental group was subjected to measure the anthropometric as well as 3site skin fold measurements. The data regarding pre and post-test of both groupscontrol and experimental were carefully recorded and entered into the computer for analyses. For this purpose, both descriptive (mean and standard deviation) and inferential statistics (Independent Samples t-Test and Paired Samples t-Test) were used for analyzing the data. The analyzed data established that the mean score of (EG) in pre and post-test were found as 28.66 and 23.5. The $t$-value of the table is 5.022 and P-value is 0.001 which is lower than the significant level $(\mathrm{P}<0.05)$.

We found that the mean pre- test BMI was 29.6 and 38.5 and post- test value was 26.4 and 38.9 in group I and II respectively. Castro et al,[14] examined whether a type of exercise favors better compliance with a prescribed diet, higher eating-related motivation, healthier diet composition or greater changes in body composition in overweight and obese subjects. One hundred and sixty-two (males $\mathrm{n}=79$ ), aged 18-50 years, were randomized into four intervention groups during 24 weeks: strength, endurance, combined strength + endurance and guideline-based physical activity; all in combination with a $25-30 \%$ caloric restriction diet. A food frequency questionnaire and a "3day food and drink record" were applied preand post-intervention. Diet and exerciserelated motivation levels were evaluated with a questionnaire developed for this study. Body composition was assessed by DXA and habitual physical activity was measured by accelerometry. Body weight, body mass index (BMI) and body fat percentage decreased and lean body mass increased after the intervention, without differences by groups. No interactions were observed between intervention groups and time; all showing a decreased in energy intake $(\mathrm{p}<0.001)$. Carbohydrate and protein intakes increased, and fat intake decreased from pre- to postintervention without significant interactions with intervention groups, BMI category or gender $(\mathrm{p}<0.001)$. Diet-related motivation showed a tendency to increase from pre- to post-intervention, without significant interactions with intervention groups, BMI or gender. Regarding motivation for exercise, gender $\mathrm{x}$ time interactions were observed. Women increased their motivation after the intervention (pre: $17.6 \pm 0.3$, post: $18.2 \pm 0.3$ ), while men maintained it. These findings suggest that there are no substantial effects of exercise type on energy intake, macronutrient selection or body composition changes. After a six-month weight loss program, individuals did not reduce their motivation related to diet or exercise, especially women. Individuals who initiate a long-term exercise program do not increase their energy intake in a compensatory fashion, if diet advices are included.

\section{CONCLUSIONS}

Regular physical activity appears to confer a health benefit to the people. There was a positive relationship between aerobic exercises and overweight women in order to reduce the value of fat in the body. 
Annals of International Medical and Dental Research

E-ISSN: 2395-2822 | P-ISSN: 2395-2814

Vol-8, Issue-1 | January-February 2022

DOI: 10.53339/aimdr.2022.8.1.1

Page no- 01-06 | Section- Research Article (Physiology)

\section{REFERENCES}

1. Visscher TL, Seidell JC. The public health impact of obesity. Annu Rev Public Health. 2001;22:355-75. doi: 10.1146/annurev.publhealth.22.1.355.

2. Pan WH, Flegal KM, Chang HY, Yeh WT, Yeh CJ, Lee WC. Body mass index and obesity-related metabolic disorders in Taiwanese and US whites and blacks: implications for definitions of overweight and obesity for Asians. Am J Clin Nutr. 2004;79(1):31-9. doi: 10.1093/ajen/79.1.31.

3. Chang HC, Yang HC, Chang HY, Yeh CJ, Chen HH, Huang KC, Pan WH. Morbid obesity in Taiwan: Prevalence, trends, associated social demographics, and lifestyle factors. PLoS One. 2017;12(2):e0169577. doi: 10.1371/journal.pone.0169577.

4. Wong Y, Chen SL, Chan YC, Wang MF, Yamamoto S. Weight satisfaction and dieting practices among college males in Taiwan. J Am Coll Nutr. 1999;18(3):223-8. 10.1080/07315724.1999.10718855.

5. Wong Y, Huang YC. Obesity concerns, weight satisfaction and characteristics of female dieters: a study on female Taiwanese college students. J Am Coll Nutr. 1999;18(2):194-200. doi: 10.1080/07315724.1999.10718850.

6. Goodpaster BH, Delany JP, Otto AD, Kuller L, Vockley J, South-Paul JE, et al. Effects of diet and physical activity interventions on weight loss and cardiometabolic risk factors in severely obese adults: a randomized trial. JAMA. 2010;304(16):1795-802. doi: 10.1001/jama.2010.1505.

7. Donnelly JE, Honas JJ, Smith BK, Mayo MS, Gibson CA, Sullivan DK, et al. Aerobic exercise alone results in clinically significant weight loss for men and women: midwest exercise trial 2. Obesity (Silver Spring). 2013;21(3):E219-28. doi: 10.1002/oby.20145.

8. Oda K, Miyatake N, Sakano N, Saito T, Miyachi M, Tabata I, et al. Relationship between peak oxygen uptake and regional body composition in Japanese subjects. JSHS. 2014;3(3):233-8. https://doi.org/10.1016/j.jshs.2012.11.006
9. O'Hagan C, De Vito G, Boreham CA. Exercise prescription in the treatment of type 2 diabetes mellitus : current practices, existing guidelines and future directions. Sports Med. 2013;43(1):39-49. doi: 10.1007/s40279-012-0004-y.

10. Williams CB, Zelt JG, Castellani LN, Little JP, Jung ME, Wright DC, et al. Changes in mechanisms proposed to mediate fat loss following an acute bout of high-intensity interval and endurance exercise. Appl Physiol Nutr Metab. 2013;38(12):1236-44. https://doi.org/10.1139/apnm-2013-0101.

11. Lee MG, Park KS, Kim DU, Choi SM, Kim HJ. Effects of high-intensity exercise training on body composition, abdominal fat loss, and cardiorespiratory fitness in middle-aged Korean females. Appl Physiol Nutr Metab. 2012;37(6):101927. doi: 10.1139/h2012-084.

12. Chiu CH, Ko MC, Wu LS, Yeh DP, Kan NW, Lee PF, et al. Benefits of different intensity of aerobic exercise in modulating body composition among obese young adults: a pilot randomized controlled trial. Health Qual Life Outcomes. 2017;15(1):168. doi: 10.1186/s12955-017-0743-4.

13. Nawaz R, Khan W, Pavlović R, Arif T, Sohail S. Effect of aerobic exercise on body composition of overweight female; inspiring university students to practice and receive more advantageous way of life. Sportlogia. 2020;16(1):110-125. http://dx.doi.org/10.5550/sgia.201601.en.nkpas

14. Castro EA, Carraça EV, Cupeiro R, López-Plaza B, Teixeira PJ, González-Lamuño D, et al. The Effects of the Type of Exercise and Physical Activity on Eating Behavior and Body Composition in Overweight and Obese Subjects. Nutrients. 2020;12(2):557. doi: 10.3390/nu12020557.

Source of Support: Nil, Conflict of Interest: None declared 